\title{
MATING SYSTEMS IN PORCELLIONID ISOPODS: MULTIPLE PATERNITY AND SPERM MIXING IN PORCELLIO SCABER LATR.**
}

\author{
CLAY SASSAMAN \\ Woods Hole Oceanographic Institution, Woods Hole, Massachusetts 02543, U.S.A. and \\ †Department of Biology, University of California, Riverside, California 92521, U.S.A.
}

Received 15.vi.78

\section{Summary}

The enzyme phosphoglucose isomerase (PGI) is encoded by a multi-allelic gene locus in North American populations of the wood louse Porcellio scaber. Laboratory crosses using virgin females have documented the Mendelian nature of PGI inheritance for seven electrophoretically distinct alleles. Several additional rare alleles occur in natural samples. This multi-allelic polymorphism has been employed to determine the frequency of multiple paternity of broods in a natural population by examining the mother-offspring (family) genotype combinations of 20 field-collected pregnant females. The data indicate that the great majority of broods ( $>80$ per cent) are multi-paternal and that each of several males usually makes a substantial spermic contribution to any particular one.

\section{INTRODUCTION}

THE mechanisms by which natural selection operates on genetic polymorphisms have as their bases differentials in both viability and fertility components of fitness. Viability components of selection are the focus of most contemporary research in population genetics, perhaps because of their greater visibility (Anderson and Watanabe, 1974). Fertility components of selection may be far more subtle (Anderson and Watanabe, 1974; Stalker, $1976 a, b)$. They may involve reproductive factors which produce no departure from Hardy-Weinberg proportions (Anderson and Watanabe, 1974), and therefore may not be reflected in studies where the primary methodology involves the counting of genotypes in samples taken from natural populations. Nevertheless, in some organisms data on the mating systems which govern the transmission of genetic information from generation to generation can be obtained with appropriate sampling protocols. Particularly convenient organisms for the study of mating systems are those in which families (mother plus offspring) can be directly collected from natural populations. Among such organisms are the porcellionid isopods (one of the families of the terrestrial order Oniscoidea) which, like all isopods, brood their young through embryonic and larval development in a marsupial pouch.

Studies on a lactate dehydrogenase polymorphism in Porcellio scaber Latr. have indicated the utility of measuring both fertility and viability components of natural selection (Sassaman, 1978). This polymorphism is characterised

* Contribution No. 4118 from the Woods Hole Oceanographic Institution.

† Present address. 
by similar frequencies of two alleles throughout the North American range of the species, despite the potential for extremely local genetic differentiation. Selection component analysis (Christiansen and Frydenberg, 1973) on this polymorphic locus indicated a marked tendency toward assortative mating, but the heterozygote deficiency generated by the mating system was apparently counteracted by heterosis in juvenile viability (Sassaman, 1978). Unfortunately, it was difficult to estimate the strength of assortative mating associated with the lactate dehydrogenase (LDH) locus. Mating anaylsis was complicated by multiple mating, and it was therefore necessary to infer the mating pattern from a correlation between allele frequencies in transmitted sperm and female genotype rather than by specifying the genotypes involved in each individual mating. In this regard, the protocol of Christiansen et al. (1974) was followed; the mating system was reconstructed from the statistical properties of allele frequencies in mother-single offspring genotype pairs. The accuracy of this approach is a function of the frequency of multiple paternities. If broods are multi-paternal but only a single offspring is sampled, then any observed assortment underestimates the true mating behaviour because it does not measure the serial correlation of mate choice by the individual multiply-mated female. Key data in evaluating the strength of non-random mating are the frequency of multiple paternities and the equitability of the spermic contributions of the various males involved in any particular family.

Multiple mating in terrestrial isopods has been extensively documented in the family Armadillidiidae, primarily on the basis of colour morphs of genetic determination (Howard, 1940; 1942; Lueken, 1962; Adamkewicz, 1969; Johnson, 1976) and has also been reported in the Porcellionidae (Sassaman, 1975). What is at issue here, however, is not the potential for multiple mating, but its incidence in natural populations.

During the course of developing additional biochemical markers of the Porcellio scaber genome I encountered a complex polymorphism for the enzyme phosphoglucose isomerase (PGI). Since a large variety of phenotypes occurred in each natural population sample, this gene system offered the opportunity of investigating mating systems underlying an apparently multi-allelic locus. Such a locus would be a sensitive indicator of the multi-paternity of individual broods, because of the large variety of potential mating types.

\section{Materials and methods}

\section{(i) Electrophoretic methods}

For animals of $10 \mathrm{mg}$ live weight or larger, a single walking leg was removed and homogenised in $25 \mu \mathrm{l}$ of extraction buffer $(0.05 \mathrm{M}$ Tris-HCl, $p H$ 7.5). With smaller animals, additional legs were removed or the entire animal was homogenised in sufficient buffer to yield a concentration of $0.25 \mathrm{mg}$ (live weight) $/ 10 \mu \mathrm{l}$ buffer. Whole-animal extracts were clarified by centrifugation at $1800 \mathrm{~g}$ for $30 \mathrm{~min}$. New-born juveniles were ground in $25 \mu \mathrm{l}$ of extraction buffer and the homogenate was applied directly to the separating gels.

Separations were conducted in horizontal starch gels (12 per cent Sigma starch) in a $\mathrm{LiOH} /$ boric acid buffer system described by Selander et al. (1971) after addition of the extract to preformed wells (25 $\mu$ l capacity) in 
the gel. A potential of $200 \mathrm{v}$ was maintained for 4-5 hours, the gels being cooled with ice trays. Phosphoglucose isomerase activity was visualised by staining the cut surface of the gel with a solution containing $0.13 \mathrm{mM}$ nicotinamide adenine dinucleotide phosphate, $0.25 \mathrm{mM}$ MTT tetrazolium, $0.02 \mathrm{mM}$ phenazine methosulphate, $0.67 \mathrm{mM}$ fructose- 6 -phosphate, $0.5 \mathrm{mM}$ $\mathrm{MgCl}_{2}$, and $0 \cdot 1$ unit glucose-6-phosphate dehydrogenase/ml in $0 \cdot 1-\mathrm{M}$ Tris-HCl buffer $(p \mathrm{H} 8 \cdot 1)$ at $32-35^{\circ} \mathrm{C}$ for $60 \mathrm{~min}$.

\section{(ii) Laboratory inheritance studies}

Virgin females for inheritance studies were obtained by growing the progeny of wild-collected pregnant females to maturity. Males were similarly obtained or were collected directly from natural populations. Juveniles were raised in mass cultures in humidified chambers on a diet of carrots, and at about 6 months age they were separated by sex. At an age of about 1 year they were typed at the PGI locus. Then known phenotypes were combined in single pair matings (or matings consisting of three females and one male) to generate backcrosses of presumptive heterozygotes of each of the seven most common alleles to the most common homozygote. After insemination and the female moult to the marsupial condition, females were isolated from the males, and the state of development of their broods was periodically monitored by visual inspection of the brood through the marsupial plates. At about 1 to 2 days before normal liberation of the brood, the progeny were dissected free of the female and the numbers of developed and undeveloped embryos were recorded. The progeny were then processed for electrophoresis and genotyped within 24 hours.

\section{(iii) Geographic distribution of variation}

The naturally occurring diversity of phenotypes and the pattern of geographic distribution in their frequencies was analysed by electrophoretic survey of samples from 17 locations in North America. Samples were collected along two essentially north-south axes, one along each coast. In most instances, samples were processed within a few days of collection. However, some population data is based on the phenotype distributions in breeding stocks cultured from a population sample made the preceding year. One population (S2) is represented by both a breeding stock derived from a collection in 1975 and a field sample made in 1976. Comparison of the genotype distributions of these two samples suggests that the pattern of variation is largely unaffected by laboratory culture conditions. Locations and collection dates for the population samples are indicated in table 1 . For those populations represented by laboratory breeding stocks, the number of pregnant females from which the stock was derived is indicated. The spatial arrangement of the central California populations is shown in Sassaman (1978) and additional data on LDH gene frequencies and sex ratios in these populations are in Sassaman (1975). Collections at ZSB and $\mathrm{CB}$ contained large numbers of pregnant females. These females were isolated from the other animals and one each of their progeny was genotyped at birth to generate gene frequency data for the 1976 cohort which could be directly compared with the adult gene frequency distributions. 
TABLE 1

Collection data for population samples of Porcellio scaber

\begin{tabular}{|c|c|c|c|c|}
\hline Location & $\begin{array}{l}\text { No. of } \\
\text { populations }\end{array}$ & Code* & $\begin{array}{l}\text { Collection } \\
\text { times }\end{array}$ & Comments \\
\hline $\begin{array}{l}\text { Massachusetts } \dagger \\
\text { (Cape Cod) }\end{array}$ & 3 & JP, HR, WH & $\begin{array}{l}\text { Oct. 1975- } \\
\text { Jan. } 1976\end{array}$ & $\begin{array}{l}\text { all within } 8 \mathrm{~km} \text { of } \\
\text { each other }\end{array}$ \\
\hline $\begin{array}{l}\text { Delaware } \dagger \\
\text { (Newark) }\end{array}$ & I & NK & Jan. 1975 & $\begin{array}{l}\text { Laboratory stock } \\
\text { from } 64 \text { females }\end{array}$ \\
\hline $\begin{array}{l}\text { North Carolina } \\
\text { (Burlington) }\end{array}$ & I & $\mathrm{BNC}$ & Jan. 1976 & Commercial source \\
\hline $\begin{array}{l}\text { Washington } \\
\text { (Seattle) }\end{array}$ & I & SL & May 1976 & 一 \\
\hline $\begin{array}{l}\text { Oregont } \\
\quad \text { (Gladstone) }\end{array}$ & I & GLD & Mar. 1977 & $\begin{array}{l}\text { Stock from } 50 \\
\text { females }\end{array}$ \\
\hline $\begin{array}{l}\text { Central California } † \\
\text { (Stanford University) }\end{array}$ & 3 & $\mathrm{~S} 1, \mathrm{~S} 2, \mathrm{~S} 3$ & Feb. 1976 & $\begin{array}{l}\text { All within } 50 \mathrm{~m} \text { of } \\
\text { each other, } \mathrm{S} 2 \\
\text { also as a stock } \\
\text { from } 100 \text { females }\end{array}$ \\
\hline $\begin{array}{c}\text { Central California } \dagger \\
\text { (Monterey Bay) }\end{array}$ & 3 & $\begin{array}{l}\text { ZSB, CB, } \\
\text { HMS }\end{array}$ & $\begin{array}{l}\text { Apr. } 1976 \\
\text { May } 1975\end{array}$ & $\begin{array}{l}\text { All within } 50 \mathrm{~km} \text { of } \\
\text { each other, HMS } \\
\text { as a stock from } 40 \\
\text { females }\end{array}$ \\
\hline $\begin{array}{l}\text { Eastern California } \dagger \\
\text { (White Mountains, } \\
\text { Owens Valley) }\end{array}$ & 2 & THS, MPC & Apr. 1977 & $\begin{array}{l}\text { High altitude } \\
\quad(>1500 \mathrm{~m})\end{array}$ \\
\hline $\begin{array}{l}\text { Southern California } \\
\text { (Riverside, San } \\
\text { Bernardino) }\end{array}$ & 2 & $\mathrm{SB}, \mathrm{SAR}$ & Jul. 1977 & - \\
\hline
\end{tabular}

(iv) Family analysis of natural matings

A sample of 35 Porcellio scaber was collected from the Woods Hole (WH) population on 7th June 1977 from beneath a single board measuring about $15 \mathrm{~cm}$ by $25 \mathrm{~cm}$. The sample included 20 females bearing marsupial plates and in the process of incubating broods. Several additional females subsequently moulted to the marsupial condition but were not included in the mating analysis on the possibility that they were inseminated after capture. All animals were typed at the PGI locus and the field-inseminated females were isolated individually and treated in the same manner as mated females produced in laboratory crosses.

After enumeration of the brood, all live-born progeny were scored for PGI genotype. Matings were then interpreted on the basis of the femalebrood genotype combinations. Three of the 20 females carried second broods, i.e., the post-partum moult was to a second marsupial pouch. For these three females, the second brood was also typed at birth, and the frequency distribution of progeny genotypes was directly compared in the two serial samples from each female.

\section{Results}

\section{(i) PGI phenotypes and their inheritance}

Gel slices stained for PGI exhibit a variety of single and triple-banded enzyme patterns which are similar to PGI electrophoretic patterns already 
described for other crustaceans (e.g., Corbin, 1977; Marvin et al., 1977). The vast majority of phenotypes ( 99.7 per cent) can be explained by postulating a complex polymorphism involving eight alleles at the structural locus encoding the protein subunit for this dimeric enzyme. Thus single-banded phenotypes would represent a variety of homozygous expressions of various alleles, and the array of triple-banded phenotypes would represent heterozygotes for various PGI structural alleles. These alleles are designated 0 through 7 in order of the decreasing mobility of their protein products in the LiOH buffer system. Triple-banded phenotypes are characterised by a more densely staining intermediate band, except in cases where the most anodal band is in the 0 position. In these very rare phenotypes, the least anodal band is typically the most densely staining. The presumed alleles 0

TABLE 2

Inheritance patterns in backcrosses to the $2 / 2$ phenotype

\begin{tabular}{cccrrrrrrrr} 
& No. of & No. of & \multicolumn{8}{c}{ Progeny phenotypes } \\
Mating type & $\begin{array}{c}\text { matings } \\
\text { progeny }\end{array}$ & $1 / 2$ & $2 / 2$ & $2 / 3$ & $2 / 4$ & $2 / 5$ & $2 / 6$ & $2 / 7$ \\
$1 / 2 \times 2 / 2$ & 1 & 9 & 4 & 5 & - & - & - & - & - \\
$2 / 2 \times 2 / 2$ & 3 & 30 & - & 30 & - & - & - & - & - \\
$2 / 3 \times 2 / 2$ & 5 & 87 & - & 41 & 46 & - & - & - & - \\
$2 / 4 \times 2 / 2$ & 5 & 81 & - & 38 & - & 43 & - & - & - \\
$2 / 5 \times 2 / 2$ & 3 & 82 & - & 42 & - & - & 40 & - & - \\
$2 / 6 \times 2 / 2$ & 4 & 58 & - & 30 & - & - & - & 28 & - \\
$2 / 7 \times 2 / 2$ & 1 & 11 & - & 7 & - & - & - & - & 4
\end{tabular}

through 7 are not, however, completely adequate to explain all PGI electrophoretic phenotypes in $P$. scaber. Several unique phenotypes have occurred in individual populations. Although these are thought to represent the expression of additional alleles, genetic analyses of these phenotypes has not been possible because of their extreme rarity. These provisional alleles include one with a homodimeric protein mobility between position 4 and position 5 (occurring in a juvenile from the WH population) and one with a band between positions 5 and 6 (occurring in the $S 2$ population). These two alleles are in frequencies below 0.0003 and have not been included in population survey summaries. In addition, an apparently new allele has recently been found in animals from Oregon (GLD) with a mobility between positions 3 and 4 . It is tentatively being included with the PGI $^{3}$ allele in gene frequency estimates for this population, pending further studies.

The direct genetic basis for the PGI polymorphism is strongly suggested by the inheritance behaviour of the phenotypes under standard breeding protocols. Progeny phenotype distributions from a variety of laboratory backcrosses are summarised in table 2. The common 2/2 phenotype breeds true, and each presumptive heterozygous phenotype shows Mendelian backcross segregation when crossed to the $2 / 2$ form. In each of the 19 individual backcross matings, the progeny phenotype distributions did not differ significantly from a $1: 1$ ratio $(P>0 \cdot 05)$. In reciprocal backcrosses the progeny segregation pattern was completely independent of the sex of the heterozygous parent. In addition to backcrosses, $2 / 4 \times 2 / 4$ and $2 / 5 \times 2 / 5$ matings have been conducted. In these crosses, the progeny phenotype distribution conformed to the expected $1: 2: 1$ genotypic ratio. 
These inheritance data suggest that PGI variation results directly from a multi-allelic polymorphism at the structural locus encoding the protein subunit of this enzyme. They also constitute negative evidence concerning other possible phenomena which might influence inheritance patterns at this marker locus. The backcross protocol employed in this study would detect the existence of "null" alleles which in combination with the PGI" allele would have been crossed to heterozygous mates. Such $2 /$ null parents would have been detected by the appearance of $i /$ null progeny in crosses with $2 / i$ parents (where $i$ represents an alternate, but active, allele). Of 328 progeny from 19 backcrosses, no such phenotypes were observed. Furthermore, the laboratory experiments do not provide any evidence for segregation distortion mechanisms, parthenogenesis, or differences in gametic or embryonic viabilities. In these aspects, the PGI inheritance data are qualitatively identical to previous studies on the LDH locus of $P$. scaber (Sassaman, 1978).

\section{(ii) Geographic variation}

North American populations of Porcellio scaber are quite diverse in their allelic constitutions at the PGI locus. Gene frequencies in the 17 populations sampled throughout the species range are given in table 3 along with a measure of the effective number of alleles, $\hat{n}_{e}$, calculated as $1 / \Sigma p_{i}{ }^{2}$ (where $p_{i}$ represents the frequency of each allele with commonness greater than 0.01 ). Although the $\mathrm{PGI}^{6}$ and $\mathrm{PGI}^{7}$ alleles can be distinguished on gels (table 2),

TABLE 3

PGI allele frequencies in North American populations of Porcellio scaber

Location

Massachusetts

JP

HR

WH

Delaware

NK (stock)

North Carolina

BNC

Washington

SL

Oregon

$$
\text { GLD (stock) }
$$

California

S1

S2

S2 (stock)

S3

ZSB

ZSB (newborns)

HMS (stock)

CB

CB (newborns)

THS

MPC

SAR

SB
No. of animals

19
65
79

32

118

31

54

64

100

24
55

55
98

98
77

24

111

78

66

71

70

44

\begin{tabular}{|c|c|c|c|c|c|c|c|}
\hline \multicolumn{8}{|c|}{ Allele } \\
\hline 0 & 1 & 2 & 3 & 4 & 5 & $6+7$ & $n_{e}$ \\
\hline- & - & 0.74 & - & 0.03 & 0.21 & 0.03 & $1 \cdot 68$ \\
\hline - & 0.04 & 0.42 & 0.07 & $0 \cdot 14$ & 0.30 & 0.03 & 3.41 \\
\hline 0.01 & 0.03 & 0.52 & $0 \cdot 12$ & 0.06 & $0 \cdot 23$ & 0.04 & $2 \cdot 91$ \\
\hline - & - & 0.22 & $0 \cdot 16$ & 0.31 & 0.25 & 0.06 & $4 \cdot 23$ \\
\hline- & 0.01 & 0.49 & 0.03 & $0 \cdot 30$ & 0.14 & 0.03 & $2 \cdot 84$ \\
\hline- & - & 0.40 & 0.03 & 0.45 & 0.06 & 0.05 & $2 \cdot 71$ \\
\hline - & - & 0.51 & $0 \cdot 17$ & $0 \cdot 12$ & $0 \cdot 10$ & $0 \cdot 10$ & 3.09 \\
\hline- & - & 0.77 & 0.05 & 0.09 & 0.02 & 0.07 & $1 \cdot 64$ \\
\hline - & 0.01 & 0.71 & 0.03 & 0.17 & 0.03 & 0.05 & 1.86 \\
\hline - & - & 0.75 & $0 \cdot 02$ & $0 \cdot 10$ & 0.02 & $0 \cdot 10$ & $1 \cdot 71$ \\
\hline - & - & 0.76 & 0.03 & $0 \cdot 10$ & 0.04 & 0.07 & $1 \cdot 68$ \\
\hline - & 0.01 & 0.45 & 0.03 & $0 \cdot 18$ & $0 \cdot 32$ & 0.02 & $2 \cdot 95$ \\
\hline- & 0.01 & 0.44 & 0.03 & 0.22 & $0 \cdot 30$ & 0.01 & 3.00 \\
\hline- & - & 0.48 & 0.06 & $0 \cdot 15$ & $0 \cdot 31$ & - & $2 \cdot 84$ \\
\hline- & - & 0.54 & $0 \cdot 10$ & $0 \cdot 19$ & 0.16 & 0.01 & 2.75 \\
\hline- & - & 0.55 & $0 \cdot 12$ & $0 \cdot 14$ & 0.19 & - & $2 \cdot 68$ \\
\hline- & - & 0.96 & 0.02 & - & 0.02 & - & 1.08 \\
\hline - & - & 0.89 & 0.07 & 0.01 & 0.04 & - & $1 \cdot 25$ \\
\hline - & - & 0.76 & 0.01 & 0.04 & 0.18 & 0.01 & 1.63 \\
\hline- & - & 0.53 & - & 0.15 & 0.32 & - & $2 \cdot 46$ \\
\hline
\end{tabular}


they are easily confused and I am uncertain of their relative frequencies in some populations sampled early in this study. Therefore these two allelic classes have been combined in population survey data (table 3 ). $\hat{\mathcal{N}}_{e}$ ranges from $\mathrm{l} .08$ (THS) to 4.23 (NK), but all populations are segregating for at least three alleles, most populations having five alleles. Comparison of allele frequency distributions of adults and progeny in the $\mathrm{ZSB}$ and $\mathrm{CB}$ populations (table 3 ) indicate that the allelic diversity is maintained during the breeding cycle.

There are no obvious geographic determinants of allele frequency. No allele consistently varies in frequency as a function of latitude and there is little evidence of differentiation between eastern and western populations. The PGI ${ }^{2}$ allele is generally the most common one but ranges in frequency from 0.22 to 0.96 . Other alleles may be either rare or absent in local populations or in relatively high frequency (e.g., $\mathrm{PGI}^{4}$ and $\mathrm{PGI}^{5}$ ).

Exceptionally high frequencies of $\mathrm{PGI}^{2}$ (and therefore low values of $\hat{n}_{e}$ ) occur in the two eastern California populations (THS and MPG). These two populations are ecologically different from the others in that they are at relatively high altitude $(>1500 \mathrm{~m})$. Whether or not this correlation represents a selective response to stressful conditions or a restriction of variation in marginal habitats is unknown.

\section{(iii) Analysis of natural matings}

The primary information on mating systems of $P$. scaber obtained in this study consists of the progeny genotype frequency distributions in each of the 20 broods produced by naturally mated females from the $\mathrm{WH}$ population (table 4). A noteworthy initial observation on breeding biology is the absence of evidence of parthenogenesis. Every one of the 20 breeding females produced families with direct evidence of outcrossing; each brood contained alleles that were not of maternal origin (table 4). This observation is in agreement with my experiences with laboratory-reared animals in suggesting that if parthenogenesis occurs, it does so in a frequency too low to detect.

For most of the natural broods (table 4), the inference of multiple mating (multiple paternity) is direct and straightforward. In broods from homozygous females (Nos. 1-10, table 4) the progeny genotype distribution simply represents the frequency distribution of the various types of fertilising sperms. Thus, if more than two progeny genotypes occur in a given brood then more than two distinct sperm types are involved in the mating and the brood is multi-paternal. For example, female No. $6(2 / 2)$ produced progeny of the following genotypes: $2 / 2,2 / 3,2 / 4,2 / 5$, and $2 / 6$, indicating fertilisations by five distinct sperm types, and therefore the participation of at least three males. Of the 10 first broods from homozygous females, seven had progeny genotype distributions that were directly (qualitatively) indicative of multiple paternity. The remaining three females (Nos. 1, 3 and 7) produced broods containing only two progeny genotypes. A quantitative argument may be advanced that these three broods also resulted from multiple mating. All three broods deviated significantly from the expected Mendelian backcross segregation ratio of $1: 1$ (none of the laboratory backcrosses involving virgin females showed this deviation). Thus, if these broods were the result of single matings, they would indicate some form of strong gametic or 


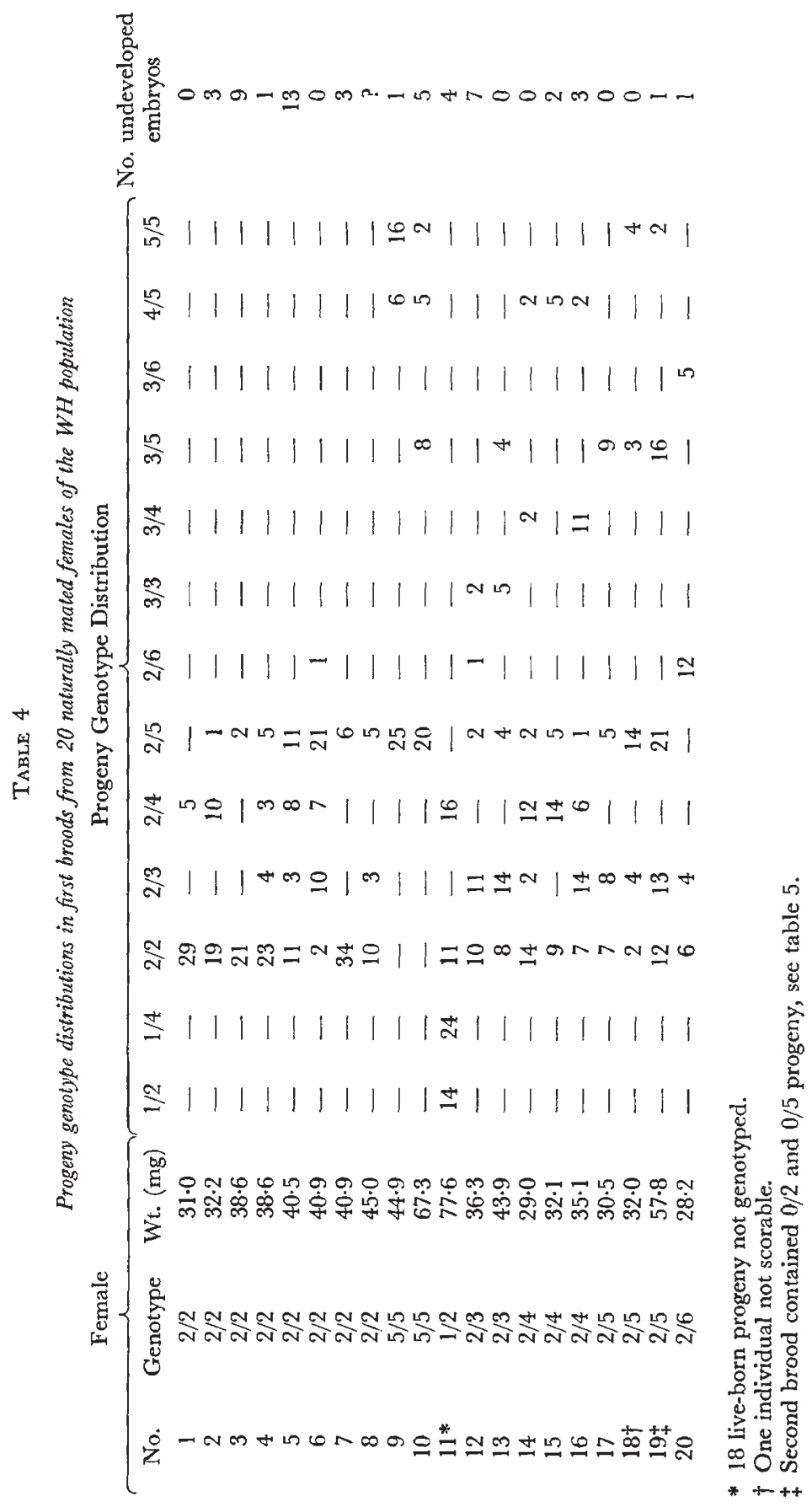


zygotic selection on the PGI alleles in field situations, which is not encountered in the laboratory. In two of the three broods (No. 1 and No. 7) a zygotic selection mechanism for the observed segregation distortion is unlikely on the basis of the low embryonic mortality (table 4). In brood 3 zygotic selection might be implicated if it is assumed that all undeveloped embryos were of genotype 2/5. Although gametic and/or zygotic selection might be involved in these three broods, I think the more plausible interpretation is that they resulted from multiple matings. All three broods were characterised by a high frequency of the $2 / 2$ genotype relative to a heterozygous form. If these distortions were selective and if such an intense selection scheme were widespread, it is doubtful that the PGI polymorphism would be as complex and as geographically widespread as it is in this species (table 3).

The remaining broods (Nos. 11-20, table 4) were from heterozygous females. A singly-mated heterozygous female can produce a maximum of four progeny genotypes. Six of the 10 females yielded broods each with five or more progeny genotypes and therefore indicative of multiple paternity. The remaining four broods (Nos. 11, 15, 17, and 20) were characterised by segregation ratios not significantly different from $1: 1: 1: 1$. These four broods were the only ones consistent with single-mating Mendelian inheritance. Thus 80 per cent of the broods produced in the WH population are interpreted to have resulted from multiple matings. This is a minimum estimate of the true incidence, because certain types of multiple matings would go undetected, even using this multi-allelic marker locus.

This high incidence of multiple-mating does not necessarily mean that several males contribute equally to a given brood. If one of the males contributes only a few sperm to a family then a high incidence of multiplemating may not have extreme effects on the mating system. However, inspection of the data (table 4) indicates that each of several males contribute substantially to a particular brood. Quantifying these contributions is somewhat less direct than measuring the actual incidence of multiple mating. The problem would be quite simple if we could specify the genotypes of each male involved in a brood. In some cases the progeny genotype distributions suggest a likely sequence of matings; for example family No. 14 (table 4) could be decomposed into-2/4 female $\times(3 / 5$ male $+2 / 2$ male) thereby yielding a $1: 1: 1: 1$ ratio $(2 / 4$ female $\times 3 / 5$ male) with a superimposed $1: 1$ ratio $(2 / 4$ female $\times 2 / 2$ male). If so, the $3 / 5$ male contributed $8 / 34$ gametes (24 per cent) and the $2 / 2$ male $26 / 34$ gametes ( 76 per cent). Similarly, family No. 6 might be interpreted as $-2 / 2$ female $\times(2 / 6$ male $+4 / 5$ male $+3 / 5$ male). This assignment is somewhat ambiguous because the same family could be generated by $-2 / 2$ female $\times(2 / 6$ male $+3 / 4$ male $+5 / 5$ male). Nevertheless, with either assignment the spermic contribution of the second most common male is substantial (on the order of 30-40 per cent). In many families, however, we cannot directly factor out two progeny distributions representing two separate matings. In fact, some families which contain only four sperm types may nevertheless be the result of triple matings (e.g., family No. 10).

Other, circumstantial, lines of evidence suggest that spermic contributions of the several males are relatively equitable. Consider the first 10 families listed in table 4 . In each one the mother is homozygous and therefore each sperm can be directly read from the progeny genotype distribution. 
If we assume that the males involved in these broods can be divided into (a) the primary male (the one making the single greatest contribution of sperm) and (b) an unknown number of additional subsidiary males, then a rough minimum estimate of the contribution of the subsidiary males might be the cumulative frequencies of the third (and subsequent) most common sperm types. Admittedly this estimate is crude, and furthermore is sensitive to different levels of bias depending upon the allelic identities of the " rare" sperm. Nevertheless, these calculations suggest that 0-33 per cent of the progeny of a particular brood stem from subsidiary matings, with an average at 13 per cent. Other evidence that more than one male makes a large contribution to the brood is preliminary data on field collected females

TABle 5

Progeny genotype distributions in sequential broods of multiply-mated females

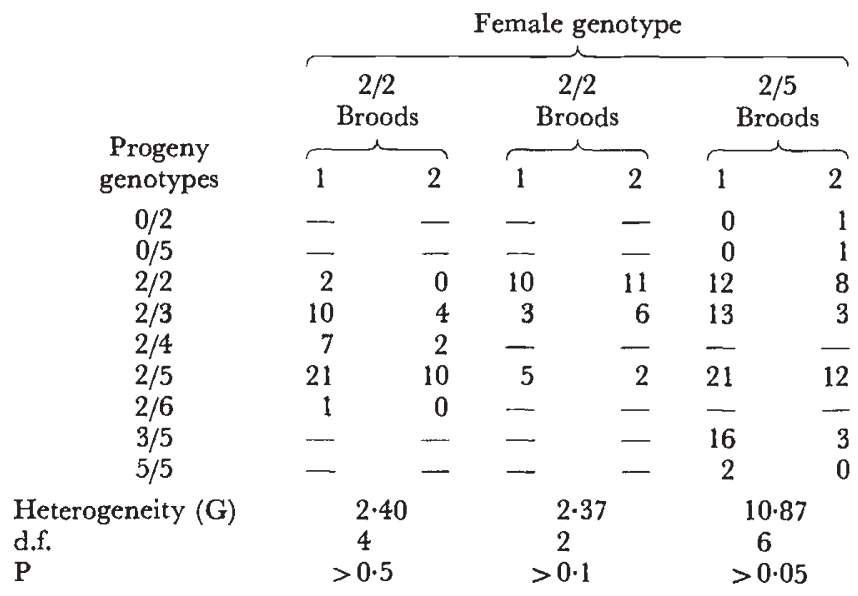

which were subsequently observed in copulo in the laboratory. In these instances the genetic identity of the most recent male is ascertainable. Analysis of several crosses to date indicate that only about 50-70 per cent of the progeny can be attributed to the last male. Thus I conclude that the observed high incidence of multiple mating does not arise because of the presence of very occasional long-lived sperm, but that the average female is carrying a mixed sperm-load in which at least two males are well represented.

A final point of interest is the nature of this mixing. Are the sperm of different males used in fertilisation in direct proportion to their relative frequencies in the female reproductive tract, or are they separated functionally? Evidence available at the moment does not address the question of spatial organisation of the sperm but does suggest that there are no shortterm changes in the usage of the sperm mix. Table 5 shows the frequency distribution of progeny types in successive broods produced by three females. In each comparison the progeny genotype distributions are homogeneous when the serial broods are analysed using the $\mathrm{G}$ statistic. Although the sperm from each male may be differentially packaged within the female, and they may be used in proportions different from their actual abundances, there is no evidence that one male's sperm contribution is exhausted before 
another male's sperm are used. In this sense, the usage of the several male contributions is functionally mixed.

\section{Discussion}

The analysis of the PGI locus has somewhat clarified our understanding of the breeding biology of Porcellio scaber. Multiple-mating is the rule, rather than the exception, in natural circumstances. The present estimate of an 80 per cent incidence in the $\mathrm{WH}$ population is a minimum estimate; certain types of multiple matings will go undetected by this technique. It is difficult to evaluate the extent of this bias without knowing with certainty the average number of matings per female. If females are generally twicemated then a substantial number of undetected multiple-matings might occur. If, however, they are typically thrice-mated, a smaller proportion of multiple matings would be undetectable. The major source of ambiguity arises from the sequential mating of a female to two different males with the same genotype (which may or may not be the same as the female's genotype). The probability that a given female will have been twice-mated to the same male genotype can be calculated from the population gene frequency distribution. This calculation for the $\mathrm{WH}$ females is as follows: the expected population genotype frequency distribution is computed from the allele frequency distribution (table 3 ) and the 28 genotype frequencies are squared and then summed. This sum $(0 \cdot 16)$ represents the probability that a given female (irrespective of her own genotype) is twice-mated to males of identical genotype, and is a minimum estimate of the frequency of undetectable multiple mating. The probability that she has not mated two identical males (and that a multiple mating would probably be detected) is therefore only 0.84 , which is quite close to the observed frequency of detection of 0.80 (table 4 ). The probability that a given female is mated to three males of identical genotype is given by the sum of the genotype frequencies cubed and is 0.036 . Assuming triple-matings as the rule, a greater proportion (0.96) of the multiple matings would likely be detected. Since some females are mated at least twice and others at least three times (table 4), it is difficult to calculate the ambiguity exactly, but the true frequency of multiple paternity is certainly greater than 80 per cent. This high incidence in the WH population is not due to an abnormally high population density. Indeed, California populations of $P$. scaber are typically of higher density than is the WH population (Sassaman, 1975). Although a large number of broods have not been examined yet, preliminary observations on the SAR population of $P$. scaber also suggest a high incidence of multiple mating. Analysis of matings in $P$. dilatatus using a bi-allelic PGI polymorphism has suggested an incidence of at least 30 per cent with a much greater ascertainment error (Sassaman and Harshman, unpublished). This latter estimate is similar to data on natural populations of Drosophila (Anderson, 1974; Milkman and Zeitler, 1974) in which there is also substantial ambiguity of ascertainment. Multiple mating appears to be a pervasive phenomenon in the porcellionid isopods and one which must be incorporated into concepts and theories about their population biology.

The general effect of a high frequency of multiple mating would be to decrease the rate of loss of variation by generalised inbreeding. Thus, more variance would be maintained in small populations. Consider, for instance, 
hypothetical circumstances with the potential for rapid fixation by drift. A mated female extracted at random from the WH population would found a new population containing an average of 3.25 alleles. She would found a population monomorphic at the PGI locus only if she and all her mates were homozygous for the same allele. If she was twice mated this would occur with a probability of $P=\Sigma p_{i}^{6}$ which, with the WH population as the source of origin, would be less than $0 \cdot 02$. Thus, the genetic variance is well buffered against even extreme bottleneck situations.

The extremely high incidence of multiple paternity bears directly on the previous study of mating systems associated with the $\mathrm{LDH}$ locus of $P$. scaber. In particular, the demonstration of assortment (Sassaman, 1978) despite a high incidence of multiple paternity (table 4) suggests that the nonrandomness associated with the $\mathrm{LDH}$ locus is a stronger phenomenon than initially thought. There appears to be sufficient behavioural discrimination arising from elements at or near the $\mathrm{LDH}$ locus to counteract the randomising tendency of additional matings. If the underlying mechanisms of LDH assortment are this strong, it may well be possible to further understand their operation under natural circumstances.

Acknowledgements. - This study was supported by a Post-doctoral Scholarship from the Woods Hole Oceanographic Institution, a fellowship from the Leopold Schepp Foundation, an intramural grant from the University of California at Riverside, and a Biomedical Research Support Grant (BRSG RR07010-12) from the Division of Research Resources, N.I.H. I thank L. Morse, R. J. Hoffmann, F. S. Chew, R. M. Yoshiyama, W. Robertson, L. R. G. Snyder, M. K. Uyenoyama, and L. Harshman for their help in obtaining field samples. J. F. Grassle kindly supplied laboratory facilities for work conducted in Woods Hole and encouraging support. J. Greever, L. R. G. Snyder, and C. Taylor, provided helpful comments on the manuscript.

\section{REFERENCES}

adamkewicz, s. L. 1969. Colour polymorphism in the land isopod Armadillidium nasatum. Heredity, 24, 249-264.

ANDERson, w. w. 1974. Frequent multiple insemination in a natural population of Drosophila pseudoobscura. Am. Nat., 108, 709-711.

ANDeRson, w. W., AND watanabe, T. K. 1974. Selection by fertility in Drosophila pseudoobscura. Genetics, 77, 559-564.

CHRISTIANSEN, F. B., AND FRYDENBERG, o. 1973. Selection component analysis of natural populations using population samples including mother-offspring combinations. Theoret. Pop. Biol., 4, 425-445.

CHRISTIANSEN, F. B., FRYDENBERG, O., GLYDENHOLD, A. O., AND SIMONSEN, v. 1974. Genetics of Zoarces populations. VI. Further evidence, based on age group samples, of a heterozygote deficit in the EstIII polymorphism. Hereditas, 77, 225-236.

CORBIN, K. w. 1977. Phosphoglucose isomerase polymorphism and natural selection in the sand crab, Emerita talpoida. Evolution, 31, 331-340.

HOWARD, H. W. 1940. The genetics of Armadillidium vulgare Latr. I. A general survey of the problems. 7. Genet., 40, 83-108.

HOWARD, H. W. 1942. The genetics of Armadillidium vulgare Latr. II. Studies on the inheritance of monogeny and amphogeny. 7. Genet., 44, 143-159.

JoHnson, C. 1976. Genetics of red body polymorphism in the isopod, Venezillo evergladensis. 7. Hered., $67,157-160$.

LUEKEN, w. 1962. Zur spermienspeicherung bei Armadillidien (Isopoda terrestria). Crustaceana, 5, 27-34.

marvin, x. T., BENTon, R. C., LANSFord, L. M., ANd GAillouet, C. W. 1977. Polymorphism in phosphohexose isomerase in white shrimp, Penaeus setiferus Linnaeus, and pink shrimp, P. duorarum duorarum. Comp. Biochem. Physiol., 57B, 95-97. 
MILKMAN, R., AND ZEITLER, R. R. 1974. Concurrent multiple paternity in natural and laboratory populations of Drosophila melanogaster. Genetics, 78, 1191-1193.

SAsSAMAN, c. 1975. Population genetics of terrestrial isopods. Ph.D. thesis, Stanford University (University Microfilms, Ann Arbor, Michigan).

sassaman, c. 1978. Dynamics of a lactate dehydrogenase polymorphism in the wood louse Porcellio scaber Latr.: evidence for partial assortative mating and heterosis in natural populations. Genetics, 88, 59I-609.

SELANDER, R. K., SMITH, M. H., YANG, S. Y., JOHNSON, W. E., AND GENTRY, J. B. 1971. Biochemical polymorphism and systematics in the genus Peromyscus. I. Variation in the old-field mouse (Peromyscus polionotus). Studies in Genetics IV, Univ. Texas Publ., 7103, 49-90.

STALKER, H. D. 1976a. Enzymes and reproduction in natural populations of Drosophila euronotus. Genetics, 84, 375-384.

STALKER, H. D. 1976b. Chromosomal studies in wild populations of Drosophila melanogaster. Genetics, 82, 323-347. 